\title{
A Contemplação Reconsiderada: Artes Performativas e Investigações da Percepção
}

QUILICI, Cassiano Sydow

\section{Resumo}

Este artigo trata das artes performativas como campo de pesquisa da percepção, abordando as potencialidades do diálogo com tradições contemplativas e o pensamento budista. Para tanto, investiga algumas proposições artísticas de John Cage e Bill Viola.

Palavras-chave: performance, percepção, contemplação.

\section{Abstract:}

This article discusses the performing arts as a field of research of perception, addressing the potential of dialogue with contemplative traditions and the Buddhist thought. For this, it investigates some artistic propositions of John Cage and Bill Viola.

Key-words: performance, perception, contemplation 
I - As "estéticas do choque" e as condições

perceptivas do homem moderno

Meu intuito aqui é sondar possibilidades da performance como campo de investigação das relações entre a ação artística e percepção contemplativa. A proposição pode soar estranha, tendo em vista que contemplação é um termo "sob suspeita" em boa parte da estética moderna e contemporânea. Em geral, é associado ao problema da recepção e do espectador, designando um comportamento meramente passivo do público diante da obra. Contemplar um quadro, uma peça etc, seria manter-se na atitude de quem está assistindo a algo sem estar implicado no que vê, protegendo-se dos efeitos desconcertantes do acontecimento artístico. Como nos mostra Rancière (2012) boa parte dos reformadores do teatro do século XX dedicaramse a atacar a posição "meramente contemplativa" do espectador, seja estimulando olhar crítico e analítico como ponto de partida da ação política (Brecht), seja arrastando o espectador para o "círculo mágico da ação teatral", proporcionando-lhe uma experiência organicamente transformadora (Artaud). Seguindo o pensamento de Benjamin ${ }^{1}$, poderíamos também articular a atitude "meramente contemplativa" do espectador com uma crença na "aura" do objeto, reforçando-se a conexão da contemplação com o universo do culto religioso que a arte moderna muitas vezes esforçou-se em se desvencilhar.

Como se sabe, a partir das vanguardas históricas a "estética do choque" tornou-se uma das principais estratégias artísticas de comunicação, propondo justamente outras formas de relação e jogo com o público. A provocação, o escândalo, a confrontação, eram meios de atacar os hábitos burgueses, retirando o indivíduo de sua zona de conforto e convocando-o a uma atitude enérgica e transformadora que pudesse fazer frente, de diferentes maneiras, aos desafios do seu tempo. Tratava-se também de recusar o lugar social predestinado à arte, os seus "templos" e "cultos", seus circuitos de circulação, inventando maneiras de desmanchar as fronteiras que circunscreviam a ação artística dentro do campo de relações sociais. Seratas, cabarets, passeios pela cidade, intervenções públicas, foram tentativas de conferir uma dimensão mais ampla ao fenômeno estético, fazendo-o irromper no cotidiano das cidades. Mais do que isso, os movimentos pretendiam desencadear transformações profundas no espírito da época, produzindo um "novo homem", uma nova sensibilidade, outras formas de subjetividade.

Curiosamente, a ideia de choque não se restringirá apenas à teoria estética, encontrando importantes ressonâncias em autores que pretendiam descrever e compreender as novas condições da sensibilidade na primeira metade do século $\mathrm{XX}$,
Refiro-me ao ensaio

"A obra de arte na era da reprodutibilidade técnica”. Ver Benjamin (1985)

2. Os movimentos de vanguarda do começo do século XX adotaram diferentes estratégias de atuação e posicionamentos políticos. A este respeito ver Fabrini (2002) 
como Simmel, Freud e o próprio Benjamin ${ }^{3}$. As novas condições de vida nas grandes cidades, o crescimento acelerado das populações, o isolamento do indivíduo e a dissolução de vínculos tradicionais, a vertiginosa transformação tecnológica, os novos meios de transporte e comunicação, o ritmo de vida, tudo isso produzirá uma profunda mudança nos padrões perceptivos e nas formas de constituição das subjetividades. A quantidade de estimulação sensorial e de informação que o homem do século XX passa a receber é muito maior do que nos tempos passados. Coloca-se assim a questão sobre a capacidade de assimilação, de metabolização psíquica desta massa de impressões, e sobre as transformações e adaptações perceptivas que elas mobilizam. Assim, um autor como Benjamin irá celebrar as possibilidades políticas das novas formas de arte que incorporam as tecnologias de reprodução das imagens (como a fotografia e o cinema) e, ao mesmo tempo, mostrar-se pessimista quanto às possibilidades do homem moderno assimilar a enorme variedade de vivências e estímulos a que está submetido transformando-as em experiências compartilháveis ${ }^{4}$.

A teorização sobre a experiência do choque surge também associada ao evento da Primeira Guerra Mundial. Os nove milhões de mortos, as novas tecnologias de destruição e a indescritível vivência nos campos de batalha influenciaram profundamente correntes de pensamento como a psicanálise. Neste caso, trata-se de pensar condições traumáticas em que a violência dos acontecimentos é dificilmente assimilável pelo "aparelho psíquico". A palavra "choque" aqui alude a condições extremas: a violência do "real" que excede qualquer possibilidade de simbolização. De forma geral, o pensamento psicanalítico insiste na importância da simbolização e da criação de formas de representação do vivido, processo fundamental para o reestabelecimento do equilíbrio psíquico. A intensidade da experiência tem que se desdobrar na linguagem, para que possa ser metabolizada.

Em alguns casos, as estéticas do choque não foram apenas contrapontos críticos a linguagens e instituições artísticas cristalizadas, que condenavam o artista a um confinamento cultural e social, sem um maior comprometimento com o seu tempo. Elas também ajudaram a intensificar as novas condições perceptivas do homem urbano, embarcando muitas vezes nas ilusões políticas e nos extremismos do seu tempo, como prova o envolvimento de artistas e movimentos com regimes totalitários (como o futurismo italiano, por exemplo). Nesses casos, elas pareciam revelar anseios mais profundos e a hybris presente em utopias políticas que ansiavam pela produção de um homem totalmente novo, desenraizado de referências fundamentais da herança ocidental.
3.

A esse respeito ver o capítulo "The notion of shock in early twenty-century Europe", em Brill (2010).

4.

Refiro-me aqui, principalmente aos ensaios "A obra de arte na era de sua reprodutibilidade técnica" e "O narrador. Considerações sobre a obra de Nikolai Leskov". 
II- Outras estéticas da percepção: a contemplação reconsiderada

Se houve certa assimilação crítica das vanguardas históricas pela cultura contemporânea, com o questionamento dos seus ideais de progresso, de suas pretensões utópicas ingênuas, da assimilação e diluição de boa parte de suas estratégia pela "sociedade do espetáculo", alguns artistas recentes têm reinventado a estética do choque, explorando dispositivos de emergência de um real muitas vezes violento e traumático na cena performática e teatral, através de performances auto-biográficas, teatro documentário, intervenções no espaço urbano, modificações do próprio corpo, entre outras estratégias ${ }^{5}$. O crescimento das formas de "artivismo", especialmente na América Latina, demonstram também a tentativa de retomar o impulso de engajamento e militância artístico-política sob novas perspectivas, buscando um sentido ampliado do estético na sua articulação com o político.

Pode-se reconhecer, no entanto, outras estratégias críticas e propositivas, em relação aos novos regimes de percepção e atenção que provocaram alterações profundas no Ocidente, a partir do final do século XIX, incluindo-se aí as novas formas de entretenimento e espetáculo. Refiro-me a um trabalho microfísico com a percepção, desenvolvido por artistas que se interessaram justamente pelo diálogo com "tradições contemplativas". Como apoio para desenvolver minhas próprias proposições nessa direção, citarei aqui dois exemplos: John Cage e Bill Viola. Vinculados, respectivamente, à música e à vídeo-arte, ambos podem ser estudados da perspectiva performática ou de uma "teatralidade expandida"6: Cage como um dos precursores dos happenings nos anos 50 e pelo evidente caráter performativo de suas intervenções ; Viola por suas vídeo-instalações, que podem ser compreendidas como dispositivos espaço-temporais em que a tela e a imagem são elementos fundamentais na criação de um ambiente para imersão do público.

O acontecimento artístico nesses casos está profundamente comprometido com a investigação de aspectos da percepção humana. Desde a época de sua formação universitária, Viola frequentava aulas sobre psicologia experimental e percepção em Syracuse, associando este interesse com a prática artística no campo do vídeo. Cage, por sua vez, toma a música como prática de depuração da capacidade da audição e de investigação das relações entre o som e silêncio. $\mathrm{O}$ som é matéria para além das categorias do musical e do não-musical (ruído). Mesmo em suas conferências, o músico adotava uma espécie de partitura, entremeando as palavras com diferentes espaços de silêncio. Ouvir a conferência implicaria também em ouvir o silêncio entre as palavras, o que normalmente não fazemos na fala cotidiana.
5 .

A este respeito ver o artigo

"Experiências do real no teatro", em Fernandes (2013).

6.

Sobre o conceito de

"teatralidade como campo expandido" ver Diegues (2014). 
Cage e Viola são também representantes de um movimento mais amplo que se dá na arte e na cultura norte-americanas do pós $2^{a}$. Guerra: o diálogo com o pensamento asiático, em especial com a filosofia e a prática Budista. Não se trata de um fenômeno que se restringe apenas à geração beat e à contra-cultura dos anos 60. Houve e continua havendo uma presença significativa de praticantes e professores das tradições do Zen Budismo, do Budismo tibetano e também da Escola Theravada em solo americano. É crescente também o numero de professores leigos e de ocidentais que se ordenam em contextos monásticos. Diversas universidades contam hoje com departamentos de estudos budistas e pesquisas avançadas sobre a questão da meditação, das práticas contemplativas ${ }^{7}$ e suas relações com as ciências cognitivas e outras áreas de conhecimento.

Cage (1912-1992) e Viola (1951- ) pertencem a gerações distintas, expressando diferentes momentos desse diálogo com o Budismo na arte americana. Explorarei alguns pontos de vista e perspectivas comuns a ambos. Para eles, a importância do diálogo com a Ásia não se resume às referências artísticas, mas abrange a filosofia e as práticas específicas de "cultivo" dos estados de corpo-mente ${ }^{8}$. Certamente pode-se encontrar nas obras de Cage apropriações inventivas de elementos da estéticas tradicionais orientais: a orquestra gamelan de Bali, a organização dos ritmos da tala indiana, a teoria dos rasa da arte hindu. Também Viola, no período que esteve no Japão entre 1980-81, fez aulas de pintura, caligrafia e entrou em contato com o teatro Nô, absorvendo princípios estéticos dessas artes no seu trabalho com vídeo-instalações. Mas o que aparece com bastante insistência no discurso destes artistas são referências ao pensamento budistas e às práticas meditativas que se estendem ao cotidiano. O modo como tais temas são abordadas e desenvolvidas revela-nos algo sobre a relação do Ocidente com uma "tradição" que, em muitos aspectos, entra em conflito com os padrões ocidentais modernos.

É marcante, no discurso de Viola e Cage, a presença de dois pensadores e divulgadores do pensamento asiático nos Estados Unidos: Ananda Coomaraswamy e D. T, Suzuki. Uma das ideias de Coomaraswamy que parecem ter exercido grande influência é a de que, do ponto de vista da experiência contemplativa, tradições espirituais Ocidentais e Orientais convergem entre si. Deste modo, seria possível traçar paralelos entre textos e práticas budistas do zen, por exemplo, com a experiência de místicos cristãos como Mestre Ekhardt e São João da Cruz. O encontro com as espiritualidades asiáticas seria também uma forma de redescoberta da mística de tradições ocidentais, obscurecidas pelos desenvolvimentos modernos das instituições religiosas no Ocidente.
7

Para uma abordagem da presença do Budismo nos EUA, ver PREBISH and TANAKA (1998).

8.

Adotamos aqui o termo

"cultivo", inspirados nos estudos de Yuasa (1993). 
Suzuki exerceu uma enorme influência na visão que o Ocidente criou sobre o Zen, enfatizando características hoje comumente associadas à essa escola: a busca de uma experiência "pura" não mediada pelos conceitos, de caráter anti-intelectual, não dualista, que necessita de um largo treinamento meditativo (zazen) e de exercícios como o Koan (especialmente na escola Rinzai) para se realizar. A noção de experiência "pura" foi elaborada também em termos filosóficos ocidentais pelo principal representante da "Escola de Kyoto", Nishida Kitaro, de quem Suziki era amigo. Nishida conseguiu estabelecer vínculos entre a experiência do Zen com discussões próprias do pensamento especulativo, sendo influenciado por autores como Henri Bergson e Willian James. Suzuki, no entanto, ressalta também certo sabor iconoclasta e humorístico do zen, alcançando fortes ressonâncias no meio artístico e cultural americano, herdeiro das correntes críticas às posturas religiosas e, ao mesmo tempo, nostálgico da experiência do sagrado.

Cage não hesita em comparar o Zen ao espírito do dadaísmo e à Marcel Duchamp. Viola muitas vezes usa os recursos da câmera lenta e da temporalidade estendida como modo de alcançar uma espécie de concentração da visão, referindo-se explicitamente a um "pure seeing" que evoca imediatamente conceitos de Nishida e Suzuki. Para especialistas em história da arte japonesa e asiática como Grotenhuis ${ }^{10}$, a reconhecida inventividade e talento de Viola não elimina o fato de que suas concepções sobre arte e pensamento Oriental e budista, por vezes, reiterem imagens e estereótipos sobre o zen e a cultura japonesa no Ocidente. Ao mesmo tempo, é inegável que tais artistas sabem explorar as relações entre questões estéticas e aspectos muito mais amplos da cultura do pensamento budista, relativos às práticas contemplativas e as formas de cultivo da mente e do trabalho com a percepção.

\section{III - Contemplação e tradição Budista}

Retomando agora a questão da contemplação a partir de outras fontes, é importante definir o termo segundo textos que servem de base e/ou ponto de partida para diversas escolas da tradição Budista. O cânone Theravada resguarda as escrituras em pali, língua em que Buda proferiu seus discursos. Nesse contexto, a ideia de contemplação é normamente associada ao termo anupassana. Segundo o monge e estudioso Bikkhu Bodhi, o termo significa um "ver de perto e repetidamente" que culmina num insight, numa apreensão profunda da realidade ${ }^{11}$. Neste sentido, a contemplação parte de um modo de percepção que se sustenta no tempo e que opera, a princípio, com um foco
9 .

Ver Viola (1995).
11.

Bikkhu Bodhi é um monge norte americano ordenado no Sri Lanka, responsável pela tradução de inúmeras obras do cânone pali (Budismo Theravada) para o inglês. Ele aborda o termo anupassana, na introdução do livro de Gunaratana (2014). 
de atenção. A primeira dificuldade deste tipo de exercício é o estado de inquietude e dispersão da mente não cultivada, sempre desejosa de novos "objetos". Sem desenvolver a capacidade de sustentar o foco de atenção numa direção determinada é difícil alcançar uma acuidade perceptiva. A atenção acaba passando superficialmente por diferentes eventos, não chegando a uma apreensão mais penetrante da instabilidade e da impermanência dos fenômenos.

É fácil reconhecer nos regimes de percepção que predominam na cultura atual uma atitude muitas vezes oposta a que descrevi acima. O estímulo à mente inquieta e insaciável, deslizando por múltiplos objetos que nunca suprem plenamente suas demandas, está na base das estratégias modernas voltadas ao estímulo do consumo. O campo do entretenimento e da diversão é preenchido também, em grande parte, por "produtos" que investem na excitação dos sentidos, o que impede a emergência e a sustentação de tempos vazios, em que poderíamos nos defrontar com os estratos mais profundos dos processos mentais. Se é inegável que existam também formas de disciplina da atenção no mundo moderno, estas, em geral, estão voltadas à execução de tarefas e das finalidades do mundo da produção e do trabalho $\mathrm{A}$ insistência de diversas obras de Bill Viola nas temporalidades estendidas de fruição, no foco em detalhes quase imperceptíveis ao olhar não treinado, e em temáticas como a morte, processos de deterioração da matéria etc, parecem querer propor um outro tipo de "educação da percepção", através do cultivo da percepção contemplativa.

Outro aspecto muito importante do exercício meditativo nas tradições budistas é o desenvolvimento de uma descriminação fina das qualidades dos fenômenos mentais. Não basta estar atento aos acontecimentos da mesma forma que alguém se mantém apegado a um objeto, ou uma pessoa totalmente envolvida com suas aversões. A qualidade do estado psico-físico desenvolvida nessas situações é marcada pela tensão e pela reatividade, impedindo uma apreensão mais acurada do que acontece. Apego e aversão expressam um desejo ilusório de um "objeto" que possa preencher plenamente nossas demandas, ou a vontade de eliminarmos tudo aquilo que nos desagrada. O exercício contemplativo implica, num primeiro momento, no reconhecimento da qualidade grosseira desses estados e no incremento de possibilidades mais livres e "purificadas"de percepção.

Quando Cage propõe que a nossa percepção auditiva deve superar os hábitos que dividem os sons "musicais" dos "ruídos", ele se confronta com uma ideia de arte que busca, em primeiro lugar, um certo tipo de deleite sensorial. Se a 
arte torna-se campo de investigação da percepção humana e dos mecanismos de apego e aversão, ela nos exigirá outra atitude. Trata-se de se suspender as associações e as histórias que imputamos aos sons, percebendo-os primeiro como qualidades de vibração, que podem ser "organizadas" de modo que se tornem mais claras para consciência. A expressão "pureza" ganha então uma nova dimensão. Significa aqui desfazer as "representações" que enredam a percepção numa série de associações (sentimentos, pensamentos, memórias etc) que tentam "fixar" a experiência. Quando conseguimos desatar essa trama através do exercício meditativo, abre-se uma nova qualidade de percepção da impermanência e da ausência de substância dos fenômenos.

\section{IV - Considerações finais}

Tentei aqui indicar algumas possibilidades de desenvolvimento do diálogo entre práticas artísticas performativas e tradições contemplativas. Tomei o exemplo de dois artistas norte-americanos, em que estas conexões alimentam a pesquisa de modos percepção envolvidas em processos criativos, conduzindo a questionamentos do próprio lugar da arte na sociedade contemporânea. A existência de tais pesquisas no campo artístico pressupõe um ambiente cultural em que o diálogo ocidente-oriente tenha adquirido certa maturidade. Mesmo que possamos criticar as limitações e distorções presentes nas proposições de Cage e Viola, é possível reconhecer, a meu ver, uma relação com o Budismo que ultrapassa as diluições e "orientalismos" presentes nas abordagens "new-age", que se caracterizam pelo ecletismo superficial e pela transformação da meditação numa espécie de "técnica" atenuadora de conflitos. A abordagem destes artistas na atual discussão sobre performance e teatro no contexto brasileiro pode colaborar para a uma compreensão mais complexa das alternativas e possibilidades de investigação da percepção e dos fenômenos da consciência no terreno da arte. 
BENJAMIN, Walter. Magia e Técnica, Arte e Política - São Paulo, Brasiliense,1985.

BRILL, Dorothée. Shock and Senseless in Dada and Fluxus London, University Press of New England (2010).

DIEGUES, Ileana. "Um Teatro sem Teatro: a Teatralidade como Campo Expandido" - em Revista Sala Preta, v.14i; São Paulo, ECA-USP.

FERNANDES, Silvia. Experiências do Real no Teatro, em Revista Sala Preta, v13ii, São Paulo, ECA-USP.

GUNARATANA, Henepola. Meditation on Perception, Boston, Wisdom Publication, 2014.

PREBISH, Charles S.; TANAKA, Kenneth K. The Faces of Buddhism in America - Los Angeles, University of California Press, 1998.

RANCIÈRE, Jacques. O Espectador Emancipado - São Paulo, Martins Fontes, 2012.

TOWNSEND, Chris. The Art of Bill Viola - London, Thames \& Hudson, 2003.

VIOLA, Bill. Reasons for Knocking at an Empty House - London, MIT Press, 1995.

YUASA, Yasuo. The Body, Self-Cultivation and Ki-energy - New York, State University of N.Y. Press, 1993. 